\title{
Reduced Lepeophtheirus salmonis larval abundance in a sea loch on the west coast of Scotland between 2002 and 2006
}

\author{
Michael J. Penston*, Colin P. Millar, Ian M. Davies \\ Fisheries Research Services Marine Laboratory, 375 Victoria Road, Aberdeen AB11 9DB, UK
}

\begin{abstract}
A survey for planktonic sea louse larvae was carried out in Loch Shieldaig, Scotland, between 2002 and 2006, and spanned 2 successive production cycles (Cycles 1 and 2) at a local Atlantic salmon Salmo salar L. farm. The vast majority of the caligid copepodids recovered were Lepeophtheirus salmonis; however, the methodology was unable to determine the species of the caligid nauplii. Greatest densities of nauplii were found at the sampling station adjacent to the salmon farm, and larval densities were low during the fallow period of both cycles. Peaks in nauplius densities occurred around the same time in the 2 cycles, but the peaks were significantly lower during Cycle 2 than Cycle 1. Lepeophtheirus salmonis copepodid densities varied temporally, but not spatially. During most of Cycle 2, copepodid densities were significantly lower than those recovered during Cycle 1. Numbers of gravid L. salmonis at the local salmon farm correlated significantly with densities of louse nauplii and $L$. salmonis copepodids in the water at time lags of 0 and 1 wk, and 1 and $2 \mathrm{wk}$, respectively. This survey demonstrated a reduction in densities of $L$. salmonis larvae in the plankton (an indication of $L$. salmonis infectious pressure) between the 2 cycles and indicated that the farm was an important source of $L$. salmonis larvae. The application of anti-louse treatments using emamectin benzoate reduced the numbers of gravid $L$. salmonis at the farm, and this was the main factor influencing the apparent reduction in $L$. salmonis infectious pressure in the loch between cycles.
\end{abstract}

KEY WORDS: Lepeophtheirus salmonis $\cdot$ Sea lice $\cdot$ Larvae $\cdot$ Salmon farm $\cdot$ Scotland

\section{INTRODUCTION}

Lepeophtheirus salmonis (Krøyer, 1838) is the dominant sea louse affecting farmed salmonids in Scotland, Norway and Ireland (Johnson et al. 2004). This sea louse occurs naturally on salmonids in the northern hemisphere, and it is not considered unusual for wild salmonids to carry a few individuals (Tingley et al. 1997, Urquhart et al. 2008). L. salmonis is largely specific to salmonids, and although infections have occasionally been reported in other groups of fish (Jones et al. 2006a, Pert et al. 2006), these should be considered as unusual (Kabata 1979) and may not enable the parasite to complete its lifecycle (Jones et al. 2006b). Among Norway, Scotland and Canada, L. salmonis costs the aquaculture industry approximately 70 million GBP per annum (Heuch et al. 2005). Another sea louse, Caligus elongatus (von Nordmann 1832), also occurs on farmed salmonids in Ireland and to a lesser degree in Scotland, but is rare in Norway (Pike \& Wadsworth 1999). C. elongatus was found to be rare in a previous plankton survey in Loch Torridon (Penston et al. 2008).

Lepeophtheirus salmonis is meroplanktonic, and infestations generally spread by the egg-bearing adult female (gravid) stage releasing nauplius I larvae, which are transported by water currents and progressively develop through the nauplius II stage to the copepodid stage. The copepodid stage is infective and searches for a host in order to survive and mature. The 
duration of each stage of development is strongly dependent on temperature (Johnson \& Albright 1991a). Under average sea surface temperatures in Loch Torridon (around $10^{\circ} \mathrm{C}$ ), L. salmonis nauplii and copepodids would last approximately 3 and $8 \mathrm{~d}$, respectively (Johnson \& Albright 1991a), but may become less capable of finding a host after just a few days as finite energy reserves dwindle (Tucker et al. 2000).

Few published accounts have described the behaviour of Lepeophtheirus salmonis larvae in the wild. Costelloe et al. (1998a,b) frequently recovered $L$. salmonis larvae near salmon farms in Ireland. They suggested that most of these larvae were probably of farm origin and that intermittent pulses of $L$. salmonis larvae that occurred near river mouths were probably of wild origin. A study in Loch Shieldaig, Scotland (Penston et al. 2008), suggested that the majority of louse larvae recovered near a salmon farm were the progeny of L. salmonis on farmed salmon. In contrast to Costelloe et al. (1998a,b), who concluded that farms only influence L. salmonis populations in their immediate environs, Penston et al. (2008) suggested that $L$. salmonis larvae can have a widespread effect in the surrounding waters.

As with most salmon farms in Scotland, Atlantic salmon Salmo salar L. farms in the Loch Shieldaig area complete a production cycle approximately every 2 yr (Revie et al. 2002). Traditionally, farms are stocked in spring with salmon smolts free of Lepeophtheirus salmonis. Harvesting can occur any time after 14 mo post-stocking (Revie et al. 2002) and is completed in the second winter. After a farm is fully harvested, the site is left fallow for $\geq 4$ wk before the next production cycle begins. Fallowing can break the life cycle of $L$. salmonis populations at farms by removing the host for a period greater than the lifespan of the larval stages, ca. $30 \mathrm{~d}$ (Grant \& Treasurer 1993, Jackson et al. 1997).

Initial infestations of Lepeophtheirus salmonis on farmed salmon most likely result from larvae released by gravid $L$. salmonis on wild sources (Bron et al. 1993b, Pike \& Wadsworth 1999, Revie et al. 2002). However, once an L. salmonis population has become established at a farm, the majority of further larvae infesting that farm will have originated from the L. salmonis on farmed fish (Tully 1989, Bron et al. 1993a,b, Revie et al.
2005). Farms monitor L. salmonis burdens on their fish, and medicinal treatments are a critical element in controlling L. salmonis infestations (Revie et al. 2002).

We conducted a plankton survey for Lepeophtheirus salmonis larvae between March 2002 and February 2006 during 2 successive production cycles (Cycles 1 and 2) of the local Atlantic salmon fish farm in Loch Shieldaig.

\section{MATERIALS AND METHODS}

Study area. Loch Shieldaig is a sea loch on the west coast of Scotland (Fig. 1) connected to adjacent lochs (Upper and Lower Loch Torridon) and the open ocean (via Lower Loch Torridon). Salmonids occur in Loch Shieldaig as livestock at 1 salmon farm and as the population of wild and stocked sea trout supported by the River Shieldaig, which discharges at the head of the loch. The sea trout migrations on this river are monitored by Fisheries Research Services using a fish trap. During this study, the sea trout smolt run generally occurred between April and June, and the return run took place typically between August and October (McKibben \& Hay 2003, 2004b, Raffell et al. 2005, 2006). Catch records from the River Balgy in the adjoining loch, Upper Loch Torridon, are maintained

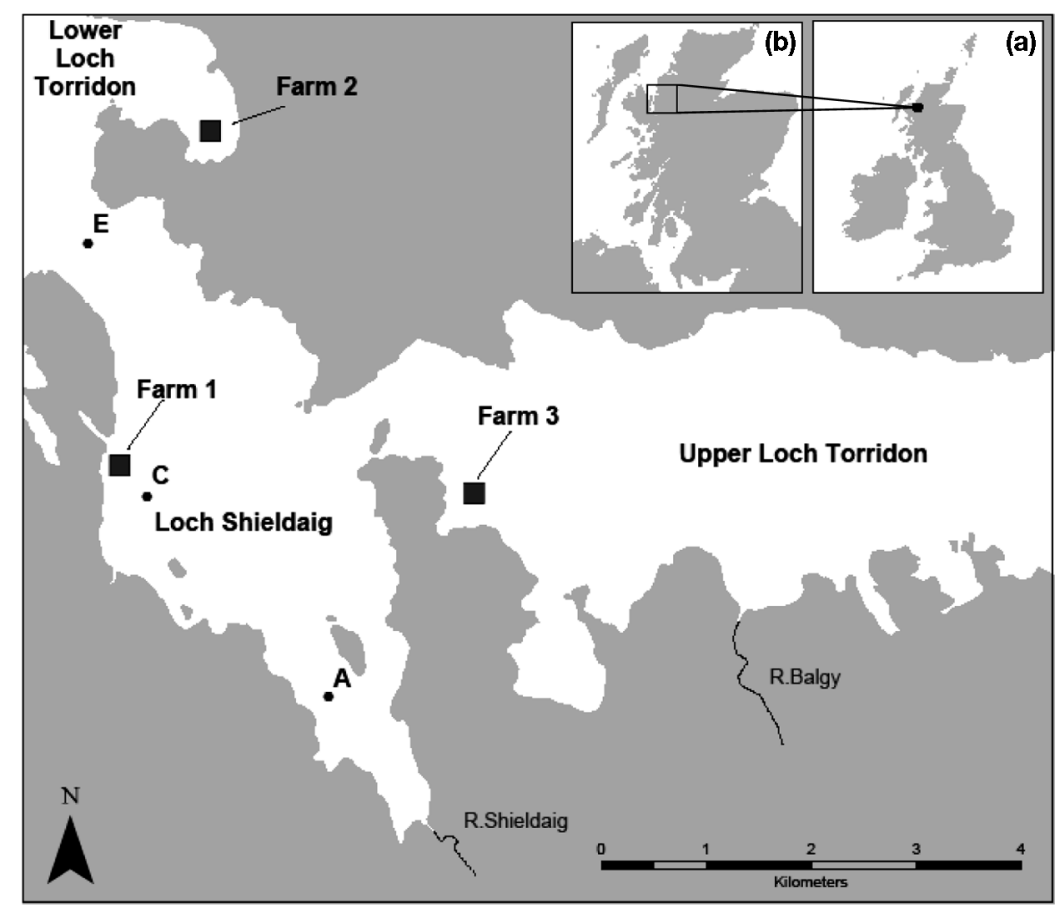

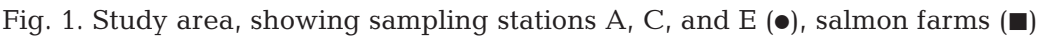
and the Rivers Shieldaig and Balgy. Inserts show location of study in relation to (a) the British Isles and (b) Scotland 
by the riparian owners. There are other salmon farms in Upper and Lower Loch Torridon in the same catchment area (Anonymous 2000), all of which, except Farm 2, follow a synchronised production cycle. The farm in Loch Shieldaig was the largest in the area, with a consented maximum biomass of $1375 \mathrm{t}$, while the 2 closest farms in the neighbouring sea lochs have consented maximum biomasses of 800 and $976 \mathrm{t}$. Detailed descriptions of the hydrography of the area are given by Murray \& Gillibrand (2006) and Gillibrand \& Amundrud (2007).

Plankton survey. Plankton samples were collected at the sea surface ( 0 to $0.5 \mathrm{~m}$ ) approximately weekly between March 2002 and February 2006 at 3 stations: Stn C was adjacent to Farm 1, and Stns A and E were approximately $2 \mathrm{~km}$ landward and seaward of Farm 1, respectively (Fig. 1). The average sample volume was $16 \mathrm{~m}^{3}\left(\mathrm{SD}=9 \mathrm{~m}^{3}\right)$. A full description of the materials and methods is provided by Penston et al. (2008).

Identification of larvae. Copepodids were identified to species using an inverted microscope (Zeiss ${ }^{\circledR}$ Axiovert 200) with reference to descriptions by Johnson \& Albright (1991b) and most particularly Schram (2004). The shape of the maxilliped and its branching barb was a key species-specific criterion for identification of Lepeophtheirus salmonis copepodids (Schram 2004). A full description of the materials and methods is provided by Penston et al. (2008), and additional details can be found in McBeath et al. (2006). Copepodids were identified in approximately $40 \%$ of the samples containing caligid copepodids, and these copepodids were recovered at a variety of stations over a range of seasons.

Gravid Lepeophtheirus salmonis counts. Salmon farms conduct regular frequent inspections of their fish to monitor Lepeophtheirus salmonis populations. Each farm company has its own protocol for monitoring $L$. salmonis, although they all follow a similar sampling design (Anonymous 2006). L. salmonis counts are conducted approximately weekly; the pens and fish sampled should be selected at random, and a total of approximately 25 fish should be examined (Treasurer \& Pope 2000). The sampling protocol for monitoring $L$. salmonis at Farm 1 was not made available despite having been requested.

Statistical analyses. The influence of station and time (production week) on nauplius and copepodid densities was investigated using Generalized Additive Models (Hastie \& Tibshirani 1990). These models allow for densities to change nonlinearly with production week and for the relationship to vary with station. The basic modelling framework follows the standard approach for count data (e.g. McCullagh \& Nelder 1989) and is detailed in Penston et al. (2008).
Penston et al. (2008) found a significant relationship between production week and log Lepeophtheirus salmonis larval density. Thus only 3 candidate models were considered here:

$$
\begin{gathered}
\log \text { density } \approx \mathrm{s}(\text { production week }) \\
\log \text { density } \approx \mathrm{s}(\text { production week })+\text { station } \\
\log \text { density } \approx \mathrm{s}(\text { production week }) \times \text { station }
\end{gathered}
$$

in which log density varies as a smooth function of production week with a shift in level between stations in the second model and a different relationship for each station in the third model (the $\times$ indicates an interaction between the variables). Each candidate model was fitted to the data, and the model with the lowest Akaike Information Criterion (AIC) was chosen. The smooth functions were constructed as penalised (thin plate) regression splines, with degrees of freedom (or bendiness) estimated during the fitting process (Wood 2006).

To investigate any association between the lice at the salmon farm and the larval lice recovered at the nearby station, cross-correlations were computed at several time lags between farm gravid counts and nauplius densities from Stn $\mathrm{C}$, and between farm gravid counts and copepodid densities from Stn C.

\section{RESULTS}

\section{Survey}

In total, 465 samples were collected: 136 contained caligid copepodids and 61 contained caligid nauplii. Numbers of nauplii and copepodids in samples ranged, respectively, from 0 to 285 and 0 to 90 . Low densities of larvae were recovered at the start and end of both production cycles. Most caligid larvae were recovered during Cycle 1, and nauplii were most abundant at Stn C (Table 1). Of the 172 caligid copepodids identified, all but 1 (which was Caligus elongatus) were identified as Lepeophtheirus salmonis.

Table 1. Number of sea louse samples (n) collected at each station and numbers of nauplii (Naup) and copepodids (Cop) recovered at sampling Stns A, C and E during 2002/2003 and 2004/2005 production cycles

\begin{tabular}{|rrrrrrrrrr|}
\hline \multicolumn{4}{c}{ A } & \multicolumn{3}{c}{ C } & \multicolumn{3}{c|}{ E } \\
& (n) Naup Cop & \multicolumn{2}{c|}{ (n) Naup Cop } & (n) Naup Cop \\
\hline $2002 / 2003$ & (70) & 10 & 566 & (70) & 599 & 293 & (69) & 67 & 153 \\
$2004 / 2005$ & (86) & 0 & 19 & (86) & 24 & 12 & $(84)$ & 1 & 13 \\
\hline
\end{tabular}




\section{Copepodid statistics}

The model selected to describe the pattern of copepodid density (copepodids $\mathrm{m}^{-3}$ ) was candidate model 1:

$\log$ density $\approx \mathrm{s}$ (production week)

There was no evidence that densities varied between stations, either in magnitude or in relation to time; therefore, station was not included in the model.

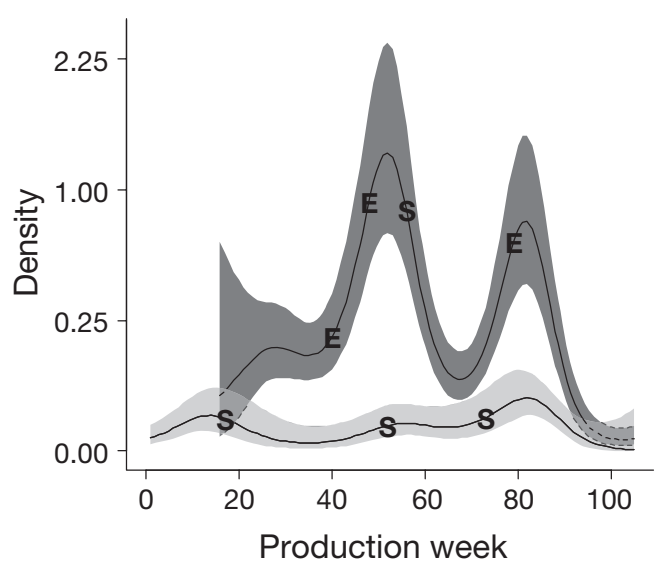

Fig. 2. Lepeophtheirus salmonis. Estimated densities (ind. $\mathrm{m}^{-3}$ on the square root scale) of copepodids at all stations with approximate $95 \%$ pointwise confidence intervals given by the shaded regions. The 2 production cycles were modelled as 1 time series but are shown here overlaid for ease of comparison. Dark and light grey shading represent production Cycles 1 and 2, respectively. Cycle 2 is plotted on top of Cycle 1 ; thus, any overlap in confidence limits and estimated means are represented by dashed lines and given an intermediate shade. Louse treatments using cypermethrin and emamectin benzoate are indicated respectively by $\mathrm{E}$ and $\mathrm{S}$
Copepodid densities were significantly lower in Cycle 2 compared to Cycle 1 from approximately production Weeks 20 to 90 (Fig. 2). Peaks occurred around Weeks 50 and 80 in Cycle 1. No peaks were evident in Cycle 2. Densities were low at the start and end of both cycles.

\section{Nauplii statistics}

The model selected to describe the pattern of nauplius density (nauplii $\mathrm{m}^{-3}$ ) was candidate model 3:

$\log$ density $\approx \mathrm{s}($ production week $) \times$ station

Because densities varied between stations both in magnitude and in relation to time (Fig. 3), station was included in the model. The temporal pattern of nauplius densities at Stn C was similar in both production cycles, although the peaks in densities around Weeks 50 and 85 were significantly lower in Cycle 2. Stn E also showed significantly lower densities around the peak in Week 40 in Cycle 2 compared to Cycle 1. The densities and numbers of recovered caligid nauplii at Stn A were low (Table 1), and no significant difference was found between the 2 production cycles (Fig. 3).

\section{Correlation statistics}

We found a significant correlation between counts of gravid Lepeophtheirus salmonis at Farm 1 and nauplius and copepodid densities recovered from Stn C at 0 and 1 , and 1 and 2 wk time lags, respectively (Fig. 4).
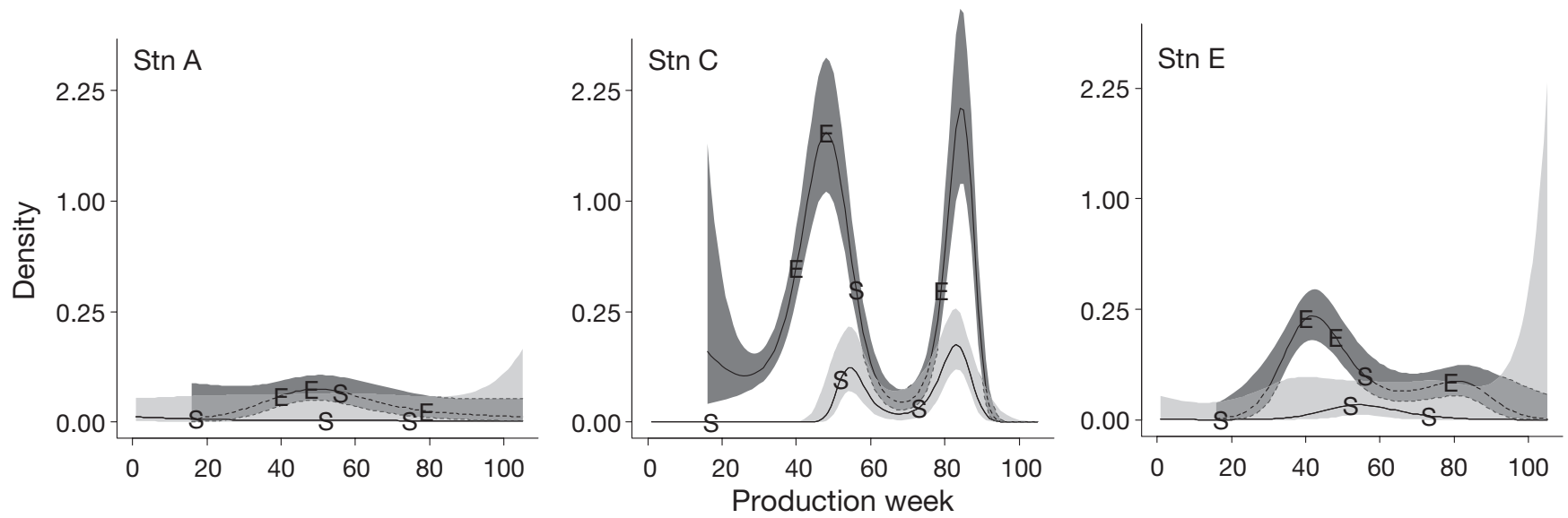

Fig. 3. Estimated densities (ind. $\mathrm{m}^{-3}$ on the square root scale) of sea louse nauplii at Stns A, C and E with approximate $95 \%$ pointwise confidence intervals given by shaded regions. The 2 production cycles were modelled as 1 time series but are shown here overlaid for ease of comparison. Dark and light grey shading represent production Cycles 1 and 2, respectively. Cycle 2 is plotted on top of Cycle 1; thus, any overlap in confidence limits and estimated means are represented by dashed lines and given a intermediate shade. Louse treatments using cypermethrin and emamectin benzoate are indicated respectively by $\mathrm{E}$ and $\mathrm{S}$ 


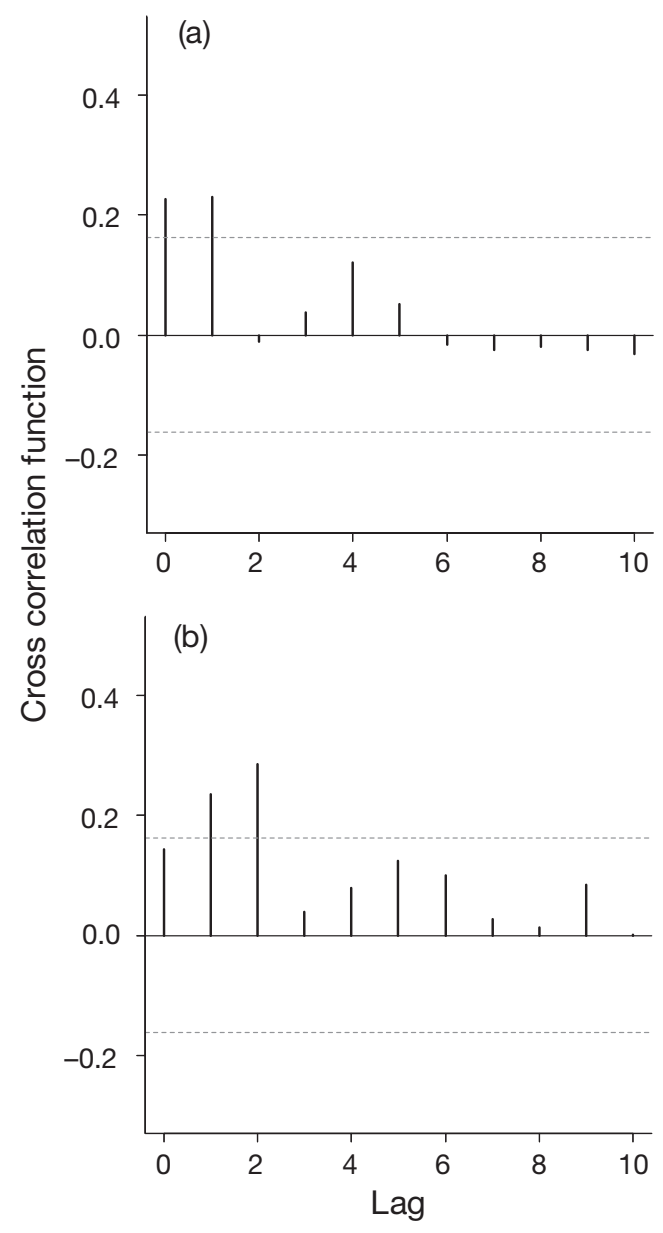

Fig. 4. Cross correlation function with time lags in weeks for farm counts of gravid sea lice with (a) nauplius and (b) copepodid densities recovered at Stn C. Correlations that lie outside horizontal dashed lines are significant at pointwise $5 \%$ level

\section{DISCUSSION}

As the vast majority of the caligid copepodids recovered in the samples were identified as Lepeophtheirus salmonis, we therefore presume that most of the caligid nauplii recovered were also L. salmonis. However, because the identity of the nauplii is presumptive, we shall refer to the nauplii generically as 'sea louse nauplii'. Previous plankton surveys in Loch Shieldaig also found L. salmonis to be the predominant louse species (McKibben \& Hay 2004a, Penston et al. 2008). Larval L. salmonis densities were significantly lower for a large part of Cycle 2 compared to Cycle 1. What caused this reduction in infectious pressure and what can be learned from it?

There are 3 main sources of Lepeophtheirus salmonis in Scottish coastal waters: wild sea trout, wild salmon, and farmed salmon. Estimations of L. salmonis larval
Table 2. Numbers of ascending wild and stocked sea trout in the River Shieldaig (data from Raffell et al. 2006) and numbers of salmon and sea trout caught on the River Balgy (data provided by Stephen Bate and Hon. Hugh Tollemache)

\begin{tabular}{|lrrrr|}
\hline & 2002 & 2003 & 2004 & 2005 \\
\hline Shieldaig ascending sea trout & 49 & 18 & 8 & 61 \\
Returning Balgy salmon & 3 & 37 & 40 & 38 \\
Returning Balgy sea trout & 80 & 10 & 0 & 0 \\
\hline
\end{tabular}

production from farms with infested salmon in Ireland, Norway, Scotland and Canada indicated that larvae from farmed sources can represent a high proportion (e.g. ca $95 \%$; Tully \& Whelan 1993, Butler 2002) of the L. salmonis larvae in coastal waters. This is largely because there are often many more farmed salmon than wild salmonids (Heuch \& Mo 2001). The numerical dominance of farmed salmon compared to wild salmonids is also true for Loch Shieldaig. On average, $<50$ sea trout returned annually to the River Shieldaig during the study, and annual catches of salmon and sea trout on the River Balgy (Upper Loch Torridon) were $<100$ between 2002 and 2005 (Table 2). The farm in Loch Shieldaig stocked 500000 Atlantic salmon smolts during both production cycles. Even presuming that only a small fraction of the returning wild sea trout and salmon on the River Balgy were caught, it is safe to assume that no more than 2000 wild salmonids ascended these rivers. There are several other small rivers in the Loch Torridon system, but their runs of salmonids are also likely to be numerically small compared to the farmed stock. Therefore, of the salmonid hosts available to L. salmonis in Loch Shieldaig, wild salmonids are estimated to represent $<1 \%$ of the total, with farmed salmon making up the rest.

Greater counts of gravid Lepeophtheirus salmonis were recorded at Farm 1 during Cycle 1 than Cycle 2 (Fig. 5), and therefore may have contributed to greater infectious pressure, as represented by greater densities of L. salmonis copepdids in the water column, on wild salmonids during Cycle 1 than during Cycle 2. Gravid L. salmonis were present between production Weeks 20 and 60 and around Week 80 in Cycle 1, whereas in Cycle 2 they were mainly reported around Week 80, although low levels (less than 0.04 gravid $L$. salmonis per salmon) were present around production Weeks 10 to 20 and 40 to 45 . The time lags of the correlation between counts of gravid L. salmonis at Farm 1 and the densities of nauplii and copepodids in the water column at Stn C were consistent with L. salmonis larval development (Johnson \& Albright 1991a). This correlation indicates that the gravid L. salmonis on the farmed salmon were an important source of sea louse larvae. 


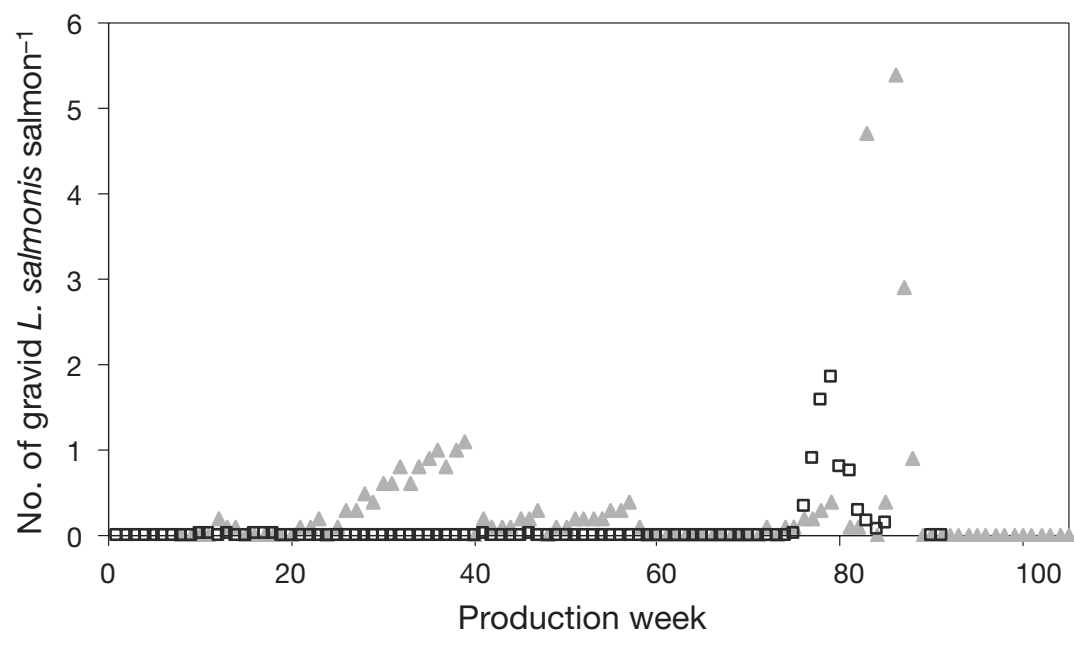

Fig. 5. Lepeophtheirus salmonis. Farm counts of gravid L. salmonis per salmon at the local farm in Loch Shieldaig during production Cycles $1(\Delta)$ and $2(\square)$

the farm (Grant \& Treasurer 1993). The low densities of nauplii and L. salmonis copepodids recovered around the fallow periods supports the supposition here that L. salmonis on farmed salmon are an important source of louse larvae.

Within our study period, the local farm used only 2 types of chemotherapeutants: the pyrethroid cypermethrin (Excis ${ }^{\circledR}$, Vericore) and the avermectin derivative emamectin benzoate $\left(\mathrm{SLICE}^{\circledR}{ }^{\circledR}\right.$ Shering-Plough Animal Health). Cypermethrin does not remove all stages of Lepeophtheirus salmonis (Hart et al. 1997), and applications of this medicine often result in short-lived decreases of 2 to $3 \mathrm{wk}$ in $L$. salmonis burdens at farms (Revie et al. 2002, Treasurer et al. 2002) and treatment success can vary (Sevatdal et al.

Plankton surveys have suggested that larval Lepeophtheirus salmonis can be carried several kilometres landward from their source (McKibben \& Hay 2004a, Penston et al. 2004, 2008), and this suggestion is supported by numerical models (Asplin et al. 2004, Murray \& Gillibrand 2006, Gillibrand \& Willis 2007). This implies that self-sustaining L. salmonis populations on farms (Tully 1989, Bron et al. 1993a,b, Jackson et al. 1997, Revie et al. 2005) might be contributing to infestation pressure in the wider environment, not just in their immediate vicinity. Costelloe et al. (1996) postulated that larvae released from lice on farmed salmon would have little effect on louse infestations outside the immediate environs of the farm. However, despite the possibility that some L. salmonis copepodids recovered in Loch Shieldaig might have been transported there from elsewhere, the bulk of the louse larvae would be expected to have been generated locally, as the largest farm in the area is located in this loch, and it is unlikely that $L$. salmonis larvae from sources other than the gravid L. salmonis on farmed salmon at Farm 1 would improve the correlation between recovered larval densities, particularly nauplius densities, and counts of gravid L. salmonis at Farm 1.

If, as this study and others suggest (Costelloe et al. 1996, 1998a,b, Penston et al. 2004, 2008), the majority of the sea louse nauplii recovered near fish farms (e.g. Stn C) are derived directly from Lepeophtheirus salmonis on farmed salmon, then L. salmonis control measures applied at the farm, such as fallow periods and treatments, would be expected to affect larval densities, particularly nauplius densities. The fallow period in the farming cycle breaks the re-infecting population of $L$. salmonis by removing the host from
2005). However, emamectin benzoate is active against chalimus, pre-adult and adult stages of L. salmonis (Stone et al. 2000a,b) and confers protection against recruitment that lasts approximately $10 \mathrm{wk}$ (Stone et al. 2000c, Treasurer et al. 2002). Therefore, applications of emamectin benzoate may provide a more detectable signal than that of cypermethrin. Environmental factors such as freshwater runoff influence the biology of L. salmonis (Bricknell et al. 2006), but do not influence the numbers of $L$. salmonis on Scottish salmon farms (Revie et al. 2003). Freshwater input would be unlikely to compromise L. salmonis at Farm 1 , as the freshwater input into Loch Torridon is relatively low (Murray \& Gillibrand 2006).

The first application of emamectin benzoate at Farm 1 was in the second year of Cycle 1. Coinciding with this treatment and a decrease in counts of gravid Lepeophtheirus salmonis at Farm 1, a decrease occurred in nauplius densities at Stn C, and in copepodid densities at all sample stations. Treasurer et al. (2002) reported that the first emamectin benzoate treatment at 2 study farms brought about an immediate decrease, and continued suppression, in numbers of L. salmonis at the farms for over 10 wk before recruitment recommenced. The cypermethrin treatments prior to the emamectin benzoate treatment may have contributed to the observed decrease in nauplius and copepodid densities prior to application of emamectin benzoate. However, as previously mentioned, L. salmonis counts at farms tend to start to increase after only a few weeks after cypermethrin treatments (Revie et al. 2002, Treasurer et al. 2002) and therefore only a short-lived decrease in nauplius densities would be expected and may have gone undetected. Furthermore, the use of a 
smoothing function in the models may overlook any short-lived changes in larval densities. The sustained period of low densities of nauplii and copepodids between production Weeks 60 and 70 of Cycle 1 occurred immediately after the emamectin benzoate treatment and is consistent with a prolonged protection against $L$. salmonis that this treatment can afford (Stone et al. 2000c, Treasurer et al. 2002).

The emamectin benzoate treatments applied in the first half of Cycle 2 appeared to have suppressed the increase in Lepeophtheirus salmonis abundance at Farm 1. Prior to the wider availability of emamectin benzoate, Revie et al. (2002) found that L. salmonis abundance typically increased on Scottish farms near the end of the first year. The numbers of $L$. salmonis at salmon farms at this stage of the cycle have an important bearing on future infestations at the farms within the same production cycle (Wadsworth et al. 1998, Revie et al. 2003). Consequently, the low counts of gravid L. salmonis at Farm 1 at the end of the first year in Cycle 2 would have promoted low L. salmonis infestation at the farm in the second half of the production cycle. L. salmonis populations at salmon farms have been linked with the larval population in the plankton (Penston et al. 2008); therefore, it appears that the efficacy of emamectin benzoate in reducing gravid $L$. salmonis numbers at Farm 1 and/or keeping them low in Cycle 2 contributed to the comparatively low larval densities in the wider loch. It is interesting to note that the emamectin benzoate treatment applied just prior to Week 80 in Cycle 2 did not appear to prevent an increase in numbers of gravid L. salmonis at Farm 1, nor in louse larval densities in the water column. Revie et al. (2002) reported that L. salmonis numbers per fish increase at farms toward the end of the production cycle and although they did not study the effects of emamectin benzoate treatments in that study, it appears that the same trend in numbers of L. salmonis was also applicable to Farm 1 despite the application of emamectin benzoate.

The coincidence of peaks in nauplius densities in both production cycles at Stn C possibly suggests that these are periods when elevated larval densities can be expected. The first and second peaks occurred around Weeks 50 and 85, respectively, which corresponds to February/March and October, respectively, in the second year of the production cycles. Revie et al. (2002) and Treasurer et al. (2002) also recorded peaks in Lepeophtheirus salmonis counts on farms at these times of year/cycle. The first peak in both production cycles in this study occurred around the time of year when strategic treatments were applied. Strategic treatments are applied around March, at a time when the parasite is at its lowest level of reproductive activity (Wadsworth et al. 1998). Strategic treatments are an industry-led effort to minimise L. salmonis burdens on farms for the rest of the year (Rae 2002, Anonymous 2006) and to minimise the burdens on farms during the spring wild smolt migration (Anonymous 2006). L. salmonis counts increase at farms during the first winter (Revie et al. 2002); therefore, a maximum could be expected just before the strategic treatments are applied, around March, after which time L. salmonis counts should be low.

Zero, or very low counts of gravid Lepeophtheirus salmonis reported at Farm 1 between production Weeks 61 and 71 in Cycle 1, and between production Weeks 0 and 75 in Cycle 2, may provide an indication of the larval densities from wild sources. During these periods, which cover a range of seasons, low levels of larval sea lice were recovered; mean and maximum densities were $0.003 \pm 0.018$ and 0.18 nauplii $\mathrm{m}^{-3}$ and $0.01 \pm 0.004$ and 0.33 copepodids $\mathrm{m}^{-3}$, respectively. These densities reflect the larval densities from wild sources in Loch Shieldaig, and densities greater than this may arise as a result of contributions from lice on salmon farms or natural epizootics. White (1940) reported an account of a natural epizootic of L. salmonis on wild salmon in Canada long before the advent of salmon aquaculture. Counts of L. salmonis at Farm 1 remained within industry guidelines (Anonymous 2006) for most of both production cycles, except around Week 80, near the end of both production cycles. Elevated counts of L. salmonis are typical on farmed salmon at this late stage of the production cycle (Revie et al. 2002). The guidelines recommend a treatment trigger level of 1.0 adult female L. salmonis per salmon between July and January, and 0.5 adult female L. salmonis per salmon between February and June when wild smolts tend to migrate. Gravid counts at Farm 1 largely remained within these recommendations in Cycle 1, yet the population of L. salmonis on the farmed salmon at Farm 1 likely contributed to increasing the larval abundance of sea lice above background densities. Perhaps infection pressure could be maintained close to background levels if farms had the ability (e.g. through medicines or husbandry) to control L. salmonis infections using more stringent trigger levels.

The survey results signify that the lower densities of sea louse nauplii and Lepeophtheirus salmonis copepodids were brought about by the improvement in $L$. salmonis control at the local salmon farm (Farm 1). The removal of gravid L. salmonis from Farm 1 during Cycle 1 and the suppression of numbers of gravid $L$. salmonis during Cycle 2 were the key elements in the apparent reduction in infectious pressure and were brought about by the application of highly effective medicinal treatments. Peaks in the density of sea louse larvae in the loch were found to occur late in the first 
winter of the production cycle, just prior to the application of strategic treatments and also near the end of the production cycle, just before farms completed harvesting. The control of $L$. salmonis infestations at salmon farms is a critical factor in the control of infestation pressure, in terms of larval abundance, in the open water of the loch away from the salmon pens. Anticipating these peaks in infectious pressure might lead to benefits in the control of $L$. salmonis at salmon farms. This study highlights the importance of L. salmonis control on farms with regard to the co-existence of healthy wild salmonid populations and salmon aquaculture.

Acknowledgements. We thank the fish farm operators in Loch Torridon for their support of this work through the Area Management Group. Thanks to Stephen Bate and Hon. Hugh Tollemache for supplying catch records from the River Balgy. Particular thanks to David Hay, Maggie McKibben, Colin Blyth, Jason Milton, Jim Raffell and Steve Buttle of FRS Shieldaig Field Station for their help with the plankton sampling and their warm hospitality.

\section{LITERATURE CITED}

Anonymous (2000) Coastal catchment zone management to avoid and minimise the effects of ISA. Aberdeen: Scottish Executive, Perth

Anonymous (2006) A code of good practice for Scottish finfish aquaculture. Scottish Salmon Producer's Organisation, Perth, p 1-22

Asplin L, Boxaspen K, Sandvik AD (2004) Modelled distribution of salmon lice in a Norwegian fjord. ICES CM 2004:11

Bricknell IR, Dalesman SJ, O'Shea B, Pert CC, Mordue Luntz AJ (2006) Effect of environmental salinity on sea lice Lepeophtheirus salmonis settlement success. Dis Aquat Org 71:201-212

Bron JE, Sommerville C, Wootten R, Rae GH (1993a) Fallowing of marine Atlantic salmon, Salmo salar L., farms as a method for the control of sea lice, Lepeophtheirus salmonis (Krøyer, 1837). J Fish Dis 16:487-493

Bron JE, Sommerville C, Wootten R, Rae GH (1993b) Influence of treatment with dichlorovos on the epidemiology of Lepeophtheirus salmonis (Krøyer, 1837) and Caligus elongatus Nordmann, 1832 on Scottish salmon farms. In: Boxshall GA, Defaye D (ed) Pathogens of wild and farmed fish: sea lice. Ellis Horwood Limited, Chichester, p 263-274

Butler JR (2002) Wild salmonids and sea louse infestations on the west coast of Scotland: sources of infection and implications for the management of marine salmon farms. Pest Manag Sci 58:595-608

Costelloe M, Costelloe J, Roche N (1996) Planktonic dispersion of larval salmon-lice, Lepeophtheirus salmonis, associated with cultured salmon, Salmo salar, in western Ireland. J Mar Biol Assoc UK 76:141-149

Costelloe M, Costelloe J, O'Donohoe G, Coghlan NJ, Oonk M, van der Heijden Y (1998a) Planktonic distribution of sea lice larvae, Lepeophtheirus salmonis, in Killary Harbour, West Coast of Ireland. J Mar Biol Assoc UK 78: 853-874

Costelloe M, Costelloe J, Coghlan N, O'Donohoe G, O'Con- nor B (1998b) Distribution of the larval stages of Lepeophtheirus salmonis in three bays on the west coast of Ireland. ICES J Mar Sci 55:181-187

Gillibrand PA, Amundrud TL (2007) A numerical study of the tidal circulation and buoyancy effects in a Scottish fjord: Loch Torridon. J Geophys Res 112:C05030

Gillibrand PA, Willis KJ (2007) Dispersal of sea louse larvae from salmon farms: modelling the influence of environmental conditions and larval behaviour. Aquat Biol 1: $63-75$

Grant AN, Treasurer JW (1993) The effects of fallowing on calligid infestations on farmed Atlantic salmon (Salmo salar L.) in Scotland. In: Boxshall GA, Defaye D (eds) Pathogens of wild and farmed fish: sea lice. Ellis Horwood Chichester, p 255-260

> Hart JL, Thacker JRM, Braidwood JC, Fraser NR, Matthews JE (1997) Novel cypermethrin formulation for the control of sea lice on salmon (Salmo salar). Vet Rec 140:179-181

Hastie T, Tibshirani R (1990) Generalized additive models. Chapman \& Hall, London

- Heuch PA, Mo TA (2001) A model of salmon louse production in Norway: effects of increasing salmon production and public management measures. Dis Aquat Org 45:145-152

Heuch PA, Bjorn PA, Finstad B, Holst JC, Asplin L, Nilsen F (2005) A review of the Norwegian 'National Action Plan Against Salmon Lice on Salmonids': the effect on wild salmonids. Aquaculture 246:79-92

Jackson D, Deady S, Leahy Y, Hassett D (1997) Variations in parasitic caligid infestations on farmed salmonids and implications for their management. ICES J Mar Sci 54: 1104-1112

Johnson SC, Albright LJ (1991a) Development, growth and survival of Lepeophtheirus salmonis (Copepoda: Caligidae) under laboratory conditions. J Mar Biol Assoc UK 71: $425-436$

Johnson SC, Albright LJ (1991b) The developmental stages of Lepeophtheirus salmonis (Krøyer, 1837) (Copepoda: Caligidae). Can J Zool 69:929-950

Johnson SC, Treasurer JW, Bravo S, Nagasawa K, Kabata Z (2004) A review of the impact of parasitic copepods on marine aquaculture. Zool Stud 43:229-243

Jones S, Kim E, Dawe S (2006a) Experimental infections with Lepeophtheirus salmonis (Krøyer) on threespine sticklebacks, Gasterosteus aculeatus L., and juvenile Pacific salmon, Oncorhynchus spp. J Fish Dis 29:489-495

Jones SRM, Prosperi-Porta G, Kim E, Callow P, Hargreaves NB (2006b) The occurance of Lepeophtheirus salmonis and Caligus clemensi (Copepoda: Caligidae) on threespine stickleback, Gasterosteus aculeatus in coastal British Columbia. J Parasitol 92:473-480

Kabata Z (1979) Parasitic Copepoda of British fishes. Ray Society, London

> McBeath AJA, Penston MJ, Snow M, Cook PF, Bricknell IR, Cunningham C (2006) Development and application of real-time PCR for the specific detection of Lepeophtheirus salmonis and Caligus elongatus larvae in Scottish plankton samples. Dis Aquat Org 73:141-150

McCullagh P, Nelder JA (1989) Generalized linear models, 2nd edn. Chapman \& Hall, London

McKibben MA, Hay DW (2003) Shieldaig Project Review June 2002-June 2003. Internal report. Fisheries Research Services, Pitlochry

McKibben MA, Hay DW (2004a) Distributions of planktonic sea lice larvae Lepeophtheirus salmonis in the inter-tidal zone in Loch Torridon, Western Scotland in relation to salmon farm production cycles. Aquacult Res 35:742-750 McKibben MA, Hay DW (2004b) Shieldaig Project Review 
June 2003-June 2004. Internal report. Fisheries Research Services, Pitlochry

Murray AG, Gillibrand PA (2006) Modelling salmon lice dispersal in Loch Torridon, Scotland. Mar Pollut Bull 53: 128-135

Penston MJ, McKibben MA, Hay DW, Gillibrand PA (2004) Observations on open-water densities of sea lice larvae in Loch Shieldaig, Western Scotland. Aquacult Res 35: 793-805

Penston MJ, Millar CP, Zuur A, Davies IM (2008) Spatial and temporal distribution of Lepeophtheirus salmonis (Krøyer) larvae in a sea loch containing Atlantic salmon, Salmo salar (L.), farms on the north-west coast of Scotland. J Fish Dis 31:361-371

Pert C, Urquhart K, Bricknell I (2006) The sea bass (Dicentrarchus labrax L.) a peripatetic host of Lepeophtheirus salmonis (Copepoda: Caligidae)? Bull Eur Assoc Fish Pathol 26: 163-165

Pike AW, Wadsworth SL (1999) Sealice on salmonids: their biology and control. Adv Parasitol 44:233-337

Rae GH (2002) Sea louse control in Scotland, past and present. Pest Manag Sci 58:515-520

Raffell J, McKibben MA, Buttle S, Hay DW (2005) Shieldaig Project Review June 2004-June 2005. Internal report. Fisheries Research Services, Pitlochry

Raffell J, Buttle S, Hay DW (2006) Shieldaig Project Review; June 2005-June 2006. Fisheries Research Services, Pitlochry

Revie CW, Gettinby G, Treasurer JW, Grant AN, Reid SW (2002) Sea lice infestations on farmed Atlantic salmon in Scotland and the use of ectoparasitic treatments. Vet Rec 151:753-757

Revie CW, Gettinby G, Treasurer JW, Wallace C (2003) Identifying epidemiological factors affecting sea lice Lepeophtheirus salmonis abundance on Scottish salmon farms using general linear models. Dis Aquat Org 57:85-95

Revie CW, Robbins C, Gettinby G, Kelly L, Treasurer JW (2005) A mathematical model of the growth of sea lice, Lepeophtheirus salmonis, populations on farmed Atlantic salmon, Salmo salar L., in Scotland and its use in the assessment of treatment strategies. J Fish Dis 28:603-613

Schram TA (2004) Practical identification of pelagic sea lice larvae. J Mar Biol Assoc UK 84:103-110

Sevatdal S, Copely L, Wallace C, Jackson D, Horsberg T (2005) Monitoring of the sensitivity of sea lice (Lepeophtheirus salmonis) to pyrethroids in Norway, Ireland and Scotland using bioassays and probit modelling. Aquaculture 244:19-27

Stone J, Sutherland IH, Sommerville C, Richards RH, Varma KJ (2000a) Field trials to evaluate the efficacy of

Editorial responsibility: Robin Overstreet, Ocean Springs, Mississippi, USA emamectin benzoate in the control of sea lice, Lepeophtheirus salmonis (Krøyer) and Caligus elongatus Nordmann, infestations in Atlantic salmon Salmo salar L. Aquaculture 186:205-219

Stone J, Sutherland IH, Sommerville C, Richards RH, Varma KJ (2000b) Commercial trials using emamectin benzoate to control sea lice Lepeophtheirus salmonis infestations in Atlantic salmon Salmo salar. Dis Aquat Org 41: 141-149

Stone J, Sutherland IH, Sommerville C, Richards RH, Endris RG (2000c) The duration of efficacy following oral treatment with emamectin benzoate against infestations of sea lice, Lepeophtheirus salmonis (Krøyer), in Atlantic salmon Salmo salar L. J Fish Dis 23:185-192

Tingley GA, Ives MJ, Russell IC (1997) The occurrence of lice on sea trout (Salmo trutta L.) captured in the sea off the East Anglican coast of England. ICES J Mar Sci 54: $1120-1128$

Treasurer JW, Pope JA (2000) Selection of host sample number and design of a monitoring programme for ectoparasitic sea lice (Copepoda: Caligidae) on farmed Atlantic salmon, Salmo salar. Aquaculture 187:247-260

Treasurer JW, Wallace C, Dear G (2002) Control of sea lice on farmed Atlantic salmon, S. salar L. with the oral treatment emamectin benzoate (SLICE). Bull Eur Assoc Fish Pathol 22:375-380

Tucker C, Sommerville C, Wootten R (2000) An investigation into the larval energetics and settlement of the sea louse, Lepeophtheirus salmonis, an ectoparasitic copepod of Atlantic salmon, Salmo salar. Fish Pathol 35:137-143

Tully O (1989) The succession of generations and growth of the caligid copepods Caligus elongatus and Lepeophtheirus salmonis parasitising farmed Atlantic salmon smolts (Salmo salar L.). J Mar Biol Assoc UK 69:279-287

Tully O, Whelan KF (1993) Produciton of nauplii of Lepeophtheirus salmonis (Krøyer) (Copepoda: Caligidae) from farmed and wild salmon and its relation to the infestation of wild sea trout (Salmo trutta L.) off the west coast of Ireland in 1991. Fish Res 17:187-200

Urquhart K, Pert CC, Kilburn R, Fryer RJ, Bricknell IR (2008) Prevalence, abundance, and distribution of Lepeophtheirus salmonis (Krøyer, 1837) and Caligus elongatus (Nordmann, 1832) on wild sea trout (Salmo trutta). ICES J Mar Sci 65:171-173

Wadsworth SL, Grant AG, Treasurer JT (1998) A strategic approach to lice control. Fish Farmer 12:8-9

White HC (1940) Sea lice (Lepeophtheirus salmonis) and death of salmon. J Fish Res Board Can 5:172-175

Wood S (2006) Generalized additive models: an introduction with R. Chapman \& Hall, Boca Raton, FL

Submitted: March 26, 2008; Accepted: June 4, 2008

Proofs received from author(s): July 28, 2008 